I Instituto Brasiliense de Direito Público (IDP), Brasília, DF, Brasil

joaopbachur@hotmail.com

https://orcid.org/0000-0002-3657-3965

João Paulo Bachur'

\title{
A PERFORMATIVIDADE DA EXCLUSÃO E AS LUTAS POR INCLUSÃO: QUESTÕES DISTRIBUTIVAS A PARTIR DA TEORIA DE SISTEMAS SOCIAIS ${ }^{1}$
}

\section{INTRODUÇÃo}

Desde que a forma inclusão/exclusão foi incorporada à teoria sociológica, a teoria de sistemas passou a contar com a possibilidade de observar fenômenos variados (e.g. diferenças novas e não somente econômicas, integrações instáveis, exclusões de diversos tipos), comparando sua perspectiva com os resultados da pesquisa tradicional sobre desigualdade social. Em vez de derivar todas as formas de exclusão ou de discriminação de uma base unitária da desigualdade, a forma inclusão/exclusão de Luhmann oferece uma nova conceitualização que evita o postulado (pressuposto) de congruência entre as diferentes esferas da vida. Inclusão no sistema econômico não implica inclusão no sistema político, jurídico ou científico; ao contrário, a forma inclusão/exclusão destaca a incongruência fundamental entre ambas as posições (Luhmann, I985, I995a, I995b, I997: 630). A esse respeito, essa forma enfatiza que as desigualdades econômicas não podem explicar todas as diferenças entre grupos e indivíduos (Stichweh, 2005: 45 et seq.).

Ainda assim, muitas questões permanecem, e o status teórico de inclusão/ exclusão ainda é controverso. Particularmente, a referida forma ofuscou um aspecto central: as questões distributivas (i.e., desigualdades sociais, nos termos clássicos da sociologia) ainda não foram discutidas a contento pela teoria de sistemas sociais. Se Luhmann pretendeu com a teoria de sistemas uma explicação universal sobre o social, é preciso encontrar uma forma de nela incorpo- 
rar a desigualdade. Nesse sentido, alega-se por vezes que a exclusão estabelece a invisibilização dos excluídos (Opitz, 2008a: 239) e que, desse modo, a questão a ser explicada é neutralizada (Kronauer, 2010: I33).

O problema talvez esteja no fato de que a teoria de sistemas concebe conflito, questões distributivas e a forma inclusão/exclusão de modo isolado.

Em primeiro lugar, o debate sobre inclusão/exclusão não faz referência ao conflito. Há muito tempo é sabido que os conflitos possuem critérios próprios de exclusão (Nollmann, I997: I9 I et seq.). Mas o modo pelo qual os conflitos podem desestabilizar e possivelmente reconfigurar os padrões de inclusão e exclusão em outros sistemas sociais requer uma análise distinta.

Em segundo lugar, o conceito de conflito é normalmente alargado de tal modo que não guarda mais nenhuma relação direta com as questões distributivas. A consequência é a descrição de um fenômeno típico da sociedade moderna não compatível ou observável com o aparato conceitual da teoria dos sistemas.

Em terceiro lugar, a forma inclusão/exclusão limita-se às relações entre indivíduo e sociedade, uma vez que ela não serve à comparação interpessoal, tendo em vista o funcionamento não coordenado dos sistemas funcionais autopoiéticos. Seu potencial de problematizar criticamente questões distributivas é, assim, neutralizado. De fato, a forma inclusão/exclusão alega trabalhar de modo transversal às questões tradicionais de distribuição.

Desse modo, o artigo oferece uma autorreflexão crítica dentro da teoria de sistemas e examina programaticamente a seguinte questão: como a inclusão e a exclusão podem ser incorporadas a uma teoria do conflito cujo cerne é constituído de questões distributivas. Para tanto, será proposta uma reinterpretação teórico-discursiva da forma inclusão/exclusão orientada para o conflito, de acordo com a qual a inclusão e a exclusão poderiam ser descritas como articulações políticas performativas, no sentido das teorias do discurso contemporâneas.

Confrontações entre a teoria de sistemas e a teoria do discurso são há muito conhecidas e não se limitam aos problemas da forma inclusão/exclusão (Stäheli, 2000; Link \& Parr, 2004; Bohn, 200I, 2008; Marchart, 2002, 2008, 2010, 20I3; Gertenbach, 2008; Opitz, 2008a). No entanto, uma utilização da forma inclusão/exclusão cujo objetivo seja a possibilidade de teorizar a comparação interpessoal ainda não foi levada a cabo.

Abordagens em teoria do discurso normalmente referem-se a mecanismos discursivos por meio dos quais a exclusão é executada. Aqueles que não ganham acesso ao discurso contam como excluídos (Opitz, 2008b: I85). Sem desconsiderar a importância dessa perspectiva, trata-se aqui, de analisar como certas reivindicações de inclusão podem ser articuladas discursivamente com recurso à demarcação de zonas ou campos de exclusão.

$\mathrm{O}$ artigo visa, assim, delinear um modelo performativo para a forma inclusão/exclusão, em cujo cerne estejam questões distributivas. Antes que o 
modelo seja esboçado, dois aspectos da teoria de sistemas de Luhmann devem ser discutidos criticamente, a saber, a despolitização do conceito de conflito e o desenvolvimento de uma teoria da inclusão/exclusão igualmente "pacificada", despida de conflito, cujo fundamento é a proibição da comparação interpessoal. A confrontação crítica com a teoria de sistemas indica a base sobre a qual se pode estabelecer uma leitura performativa da forma inclusão/exclusão. O objetivo dessa leitura consiste na ativação de um potencial crítico da teoria de sistemas segundo o qual inclusão e exclusão são compreendidas como fatores da estruturação discursiva dos conflitos distributivos.

\section{A DESPOLITIZAÇÃO DO CONFLITO}

A teoria de sistemas de Luhmann dispõe de um conceito ambivalente de conflito: é linguisticamente ampliado e politicamente reduzido. $\mathrm{Na}$ teoria de sistemas, o conflito é definido como o "não" comunicado:

Falaremos, então, de conflito sempre que uma comunicação for contraditada. Isso poderia ser formulado também do seguinte modo: quando uma contradição é comunicada. O conflito é a autonomização de uma contradição por meio da comunicação. Assim, um conflito se apresenta apenas quando expectativas são comunicadas e a não aceitação da comunicação é comunicada de volta. (Luhmann, I984: 530).

Desse modo, o conflito é a mensagem que recusa uma oferta de comunicação e estrutura um subsistema parasitário no sistema principal, de modo que a própria integridade do "sistema hospedeiro", por assim dizer, é ameaçada (Luhmann, I984: 53I).

O ganho sociológico dessa definição consiste na teorização do conflito de modo independente das "condições estruturais" (Dahrendorf, I990) externas que estariam situadas além da constituição comunicativa da realidade social, como se os conflitos pudessem simplesmente ser delas derivados. De acordo com as suposições da teoria de sistemas, a comunicação é a operação basilar da sociedade, e nenhuma base extracomunicativa e puramente econômica deve ser pressuposta. O conflito estrutura expectativas, orienta a conduta e permite cálculos de cursos de ação. Trata-se de uma "solução negativa" para o problema da dupla contingência: "Eu não faço o que você gostaria se você não fizer o que eu gostaria" (Luhmann, i984: 531).

No entanto, seria o "não" dito suficientemente agudo para expressar a dinâmica de todos os conflitos possíveis? Nesse ponto, Luhmann parece aceitar subliminarmente uma variação das teorias típicas dos atos de fala, em oposição à sua teoria da comunicação (Luhmann, I984: 258). No que se refere ao conceito de conflito de Luhmann, a recusa oral segue de modo demasiadamente estreito a expressão falada. Ainda que a teoria dos atos de fala seja recusada explicitamente como base de Luhmann (I997: 257 et seq.), o conflito continua a ser definido intimamente com a expressão da fala. Daí a banalização do con- 
flito: "Normalmente, recusas são eventos banais, conflitos nos menores sistemas que surgem no nível da interação sem consequências sociais de grande alcance e esvanecem" (Luhmann, I984: 54I). Por conseguinte, um conflito deve surgir espontaneamente. ${ }^{2}$ Um evento banal, como uma recusa oral mínima, intensifica-se rapidamente por qualquer motivo e torna-se um conflito, que chega a um sistema (Luhmann, I984: 534).

Contudo, as supostas alta arbitrariedade e espontaneidade dos conflitos, assim como seu caráter banal, não correspondem às características do conflito político no capitalismo democrático (Streeck, 20I I). Está completamente claro que deve haver uma distância considerável entre banalidades acidentais e a durabilidade de relações que moldam a conduta dos participantes (Messmer, 2003: 98-99). Mas essa distância não é facilmente reconciliável com o "não" comunicado. E também está claro que os conflitos devem surgir de modo processual (Giegel, I998: I6), se eles consistem apenas de comunicação. Mas a concepção excessivamente verbal do evento da recusa põe em xeque justamente a capacidade do conceito de conflito de explicar a diferenciação de um sistema parasitário. Do "não" comunicado não decorre necessariamente uma intensificação da contradição. Então, como uma recusa banal chega a um conflito?

Wolfgang Ludwig Schneider (I994: 202) propõe um modelo cujo cerne consiste em um segundo "não": somente a recusa a uma recusa potencializa a contradição, precisamente pelo fato de que a ordem interna de um sistema substitui sua preferência pelo consenso por uma preferência pela recusa (Schneider, I994: 206). Com base na análise da conversação, outra abordagem enfatiza a distinção entre não compreensão e não aceitação, para atribuir exclusivamente a esta o conflito, de modo que uma recusa apenas chega a conflito se estiver embutida em uma longa cadeia comunicativa (Messmer, 2003: I I0). O objetivo consiste em superar o "não" singular e concretizar, nos termos da teoria da conversação, a intensificação de recusas. Essa intuição demonstra que um evento inofensivo de recusa chega a tema público, de modo que a discussão ganha uma dinâmica própria e produz estabilidade (Nollmann, I997: I05).

Essas abordagens até podem oferecer soluções técnicas e teóricas plausíveis para o problema da intensificação dos conflitos, mas as questões de distribuição passam despercebidas. No entanto, questões distributivas pertencem ao cerne dos conflitos políticos das democracias hodiernas. Sem as levar em consideração, a teoria de sistemas corre o perigo de perder de vista a especificidade política do conflito. O "não" comunicado atua como critério de identificação dos conflitos distributivos e da comunicação marcada pelo dissenso que ocorre regularmente em uma infinidade de interações cotidianas.

A assimilação do conflito à recusa falada dificulta a distinção entre conflitos distributivos e recusas banais. Assim, dado que nem toda recusa oral estrutura uma discussão pública ou institucional a respeito do alcance das 
prestações dos sistemas funcionais ou da participação em suas comunicações, o conceito de conflito resta impreciso para a descrição das lutas políticas. De um lado, os conflitos só podem ocorrer enquanto comunicação no âmbito da recursividade operativa de um sistema autopoiético. Um conflito surge necessariamente da comunicação. De outro, é definido exclusivamente no sentido de uma recusa linguística que sugere a noção de um ato de fala isolado, de modo que se abre uma fenda entre cada recusa fragmentada a ofertas de comunicação e discussões acumuladas que possam ter efeitos sobre os sistemas parciais da sociedade.

Um sistema pode até ser compreendido como a estruturação comunicativa de uma contradição, mas ele não surge necessariamente de modo espontâneo, isto é, como decorrência de uma intensificação relativamente arbitrária de recusas orais, como afirma Luhmann. Muitos conflitos não resultam arbitrariamente de negações banais acidentais; eles são antes deliberadamente formulados para problematizar determinados temas, por exemplo, questões distributivas.

Esse estreitamento tem raízes no foco exclusivo no "não" falado assim como na imputação do acaso como pretensa solução para as questões de distribuição: "Mas por que ela [a estratificação] persiste de qualquer modo? A resposta só pode ser que a diferenciação sistêmica funcional não regula essas questões. Seus subsistemas são voltados para a resolução de problemas e a aquisição de recursos.

Nesse ponto, a teoria de sistemas ganha contornos quase hayekianos, mesmo que a distância entre Hayek e Luhmann não seja apagada. Destaca-se um importante paralelismo teórico relacionado ao papel do acaso nas questões de distribuição: tal como Hayek (I976: I07), Luhmann exclui a necessidade de discutir teoricamente as questões distributivas, posto que o acaso é responsável pela explicação das desigualdades empíricas. Hayek (I973: 35 et seq.) argumenta que o mercado é uma ordem anônima e espontânea, cujo resultado não pode ser julgado como justo ou injusto, dado que somente a conduta individual pode ser objeto de valorações morais. Por esse motivo, os efeitos distributivos são abandonados ao acaso. Para Luhmann, o acaso se impõe uma vez que inclusão e exclusão devem operar de modo incongruente. As questões distributivas são assim excluídas operativamente (e não moralmente), mas sendo deixadas ao acaso. ${ }^{3}$

O acaso impede a conexão entre as questões de distribuição e o conflito, uma vez que este se limita ao "não" comunicado. Desse modo, o conceito de conflito de Luhmann é despolitizado. A repolitização do conflito depende de sua conexão com a forma inclusão/exclusão. Esta, por sua vez, é neutralizada pelo fato de não permitir uma comparação interpessoal. 


\section{A NEUTRALIZAÇÃO DA FORMA INCLUSÃO/EXCLUSÃo}

A conceitualização da forma inclusão/exclusão com dois lados (Luhmann, I995a, I995b, I995C) suscitou uma discussão acalorada de tamanhas proporções que é quase impossível dar conta da literatura crítica correspondente (cf. Göbel \& Schmidt, I998; Bohn \& Hahn, 2002; Stichweh, 2005; Farzin, 2006; Bohn, 2008; Schroer, 2010; Bachur 2012).

A forma inclusão/exclusão tem uma história de desenvolvimento ímpar. Enquanto alguns conceitos como "sistema", "estrutura”, "função", "expectativa" foram utilizados e elaborados desde o início, e outros como "autopoiese", "acoplamento estrutural", "observação de primeira e segunda ordem" emergiram apenas com a "guinada autopoiética", a forma inclusão/exclusão foi desenvolvida de modo espasmódico. Ao contrário de ambas as orientações, ela teve uma carreira aos saltos, na qual é possível reconhecer três espasmos: (i) inclusão como prestação progressiva da diferenciação funcional; (ii) inclusão no sentido de interpenetração; (iii) inclusão como o lado interno de uma forma de dois lados.

Ad (i). Luhmann recorre ao conceito de inclusão de Parsons e T. H. Marshall; a inclusão é pensada sem um lado reverso e está relacionada à progressão da diferenciação funcional e ao surgimento correlato de uma semântica de inclusão total amparada nos direitos fundamentais (Luhmann, I975: 200, I977: 236-237, I980a: 332, I965). Embora o problema da desigualdade empírica já fosse reconhecido (Luhmann, I98I: 25), imperava uma combinação harmônica entre diferenciação funcional e inclusão: "o princípio da inclusão de todos em todos os sistemas funcionais vale como postulado e, em medida crescente, também na realidade" (Luhmann, I980b: 3I, grifos no original).

Ad (ii). A inclusão é conceitualizada tendo como base o conceito de interpenetração, ao passo que a exclusão emerge como individualidade da exclusão (Luhmann, I989: I58). Nesse momento, a exclusão ainda não é o lado negativo da inclusão, mas uma condição de possibilidade da própria inclusão.

Para apreender isso, pretendemos diferenciar inclusão e exclusão. Interpenetração leva à inclusão, posto que sistemas disponibilizam sua complexidade uns aos outros, utilizando-as reciprocamente. Mas ela conduz também à exclusão, uma vez que sistemas em situação de interpenetração têm de se manter como sistemas autopoiéticos distintos uns dos outros, como condição de possibilidade da própria interpenetração (Luhmann, I984: 299, grifos meus).

A participação na comunicação funcionalmente diferenciada não depende mais do pertencimento a um estamento, família, ordem ou classe. A possibilidade de participar da comunicação jurídica, política, científica depende apenas da maneira pela qual cada sistema parcial disciplina especificamente seus critérios de participação. A exclusão marca, assim, uma transição no modo de constituição da individualidade, da inclusão para a da exclusão (cf. Bohn, 2006: 49 et seq.). 
Ad (iii). Por fim, no sentido de George Spencer-Brown (I969), inclusão designa o lado interno da forma, cujo lado externo é a exclusão (Luhmann, I 995a: 229). Além disso, a distinção entre pessoa e corpo também é introduzida (Luhmann, I99I) para expressar a diferença entre simbólico e simbiótico. Dessa maneira, o lado da exclusão é o terreno do puramente físico, não mediado simbolicamente:

Os mecanismos simbióticos dos meios de comunicação perdem sua ordenação simbólica específica. Violência física, sexualidade e satisfação elementar e pulsional de necessidades são liberadas e tornam-se imediatamente relevantes sem ser civilizadas por meio de recursos simbólicos (Luhmann, I997: 633).

A inclusão assinala o lado interno de uma forma cuja lado externo é a exclusão; de um lado, há comunicação por meio da marcação de pessoas, do outro lado, os corpos, enquanto pura materialidade, são comunicativamente inatingíveis e, por isso, irrelevantes. Por fim, Luhmann introduziu outra dimensão, a saber, a endereçabilidade no âmbito da operação comunicativa de um sistema (Luhmann, I995a: 238). Esta refere-se a um fenômeno muito específico, que enfatiza a prestação particular da comunicação de marcar pessoas (Fuchs, I997).

Contudo, no percurso do desenvolvimento da forma inclusão/exclusão, essas três etapas não foram apresentadas em uma conceitualidade unitária (Göbel \& Schmidt, I998; Farzin, 2006). Em um momento, exclusão é o lado reverso necessário da inclusão, dado que a inclusão só ocorre "quando a exclusão é possível” (Luhmann, I997: 62I). Em outro momento, impera uma proibição generalizada da exclusão que bloqueia a convertibilidade de recursos de um sistema para outro, dado que nenhuma pessoa pode ser excluída da sociedade (Luhmann, 2000a: 232). Ocorre uma pergunta: "como pode haver inclusão se não há exclusão?" (Luhmann, I995b: I46-I47). Mas há sim exclusão quando a exclusão de um sistema funcional leva à de outros (Luhmann, I995b: I47). Em suma: há inclusão justamente quando há exclusão, dado que inclusão e exclusão são dois lados de uma forma, mas ninguém pode ser excluído da sociedade - logo, não há exclusão; mas exclusão significa o acúmulo empírico de exclusões dos sistemas funcionais, então há exclusão. Vê-se que mesmo Luhmann não conseguiu burilar o potencial crítico da forma inclusão/exclusão, oscilando de um lado para outro.

A aporia emana da fusão de três níveis na formação do conceito, que não são dissociados, mas que tampouco podem ser reduzidos um ao outro, a saber: o nível operativo da interpenetração; o nível empírico do acúmulo de exclusões de alguns sistemas funcionais; e o nível discursivo da endereçabilidade das pessoas. As três dimensões só se tornam completamente claras nos textos dos anos I990. Essa composição em três etapas é constitutiva da forma inclusão/ exclusão, de modo que uma aporia é inerente a essa distinção. Uma citação relativamente longa ilustra esse caráter compósito, com nossas inserções entre colchetes: 


\begin{abstract}
Do ponto de vista da teoria sociológica de sistemas, inclusão/exclusão sempre significam a inter-relação entre sistemas sociais e sistemas psíquicos, estes sendo sistemas autônomos e, logo, pertencentes ao ambiente dos sistemas sociais [nível operacional: interpenetração]. Inclusão e exclusão, assim, indicam a maneira pela qual os sistemas psíquicos enquanto pessoas são endereçados ou levados em consideração nos processos comunicativos dos sistemas sociais [nível discursivo: endereçabilidade]. [...] O que hoje normalmente se designa com o conceito de exclusão não é o evento de exclusão única, que não é problemático na maioria dos casos. Se uma pluralização de participações e afiliações é caraterística da sociedade moderna, então é provável que todos os indivíduos sejam excluídos em alguns aspectos relevantes. Talvez a pessoa não se interesse por música, ou não seja religiosa ou não acredite na utilidade e relevância social dos esportes, e assim por diante. Mas a exclusão obviamente torna-se um problema se ocorre repetidamente nas interações com sistemas sociais plurais e se essas exclusões forem conectadas sequencialmente [nível empírico: cúmulo de exclusões] (Stichweh, 2002, I03-I04).
\end{abstract}

Mas as relações entre esses eixos conceituais são deveras problemáticas: a interpenetração é um pressuposto operativo dos sistemas autopoiéticos, enquanto o acúmulo de discriminações empíricas é o efeito colateral das operações dos sistemas funcionais, e a endereçabilidade significa a marcação discursiva de pessoas. Além disso, as relações entre os níveis são assimétricas. A distribuição factualmente desigual de prestações do sistema pode até condicionar em alguma medida (mas não necessariamente) o modo da endereçabilidade, que, contudo, é um pressuposto para que as desigualdades venham a ser comunicadas - diferenças fáticas só adentram a comunicação quando são tornadas visíveis e articuladas comunicativamente por meio da vivência e da ação. Em ambos os casos, a interpenetração é meramente o acoplamento de sistemas fechados e desconhece nuança ou desigualdade. A interpenetração não pode ter qualquer efeito sobre a distribuição de prestações do sistema e de oportunidades comunicativas. Isso porque ela é apenas uma condição ecológica, um pressuposto lógico da coesão operativa e da formação do sistema (Luhmann, I984: 297). A interpenetração não pode ser condicionada e também não condiciona coisa alguma. Fundamentalmente, o mero fato de que os sistemas da consciência e os sistemas sociais devem ser acoplados estruturalmente uns com os outros para que suas operações autopoiéticas possam ocorrer não diz nada sobre o modo como as pessoas operam como endereço para comunicação no âmbito de sistemas funcionais e, menos ainda, sobre a história prévia de acúmulo de vantagens ou discriminações funcionais. Assim consolida Luhmann uma constituição aporética da forma inclusão/exclusão, de modo que ela pode significar a um só tempo interpenetração, participação factualmente desigual nas operações dos sistemas sociais e endereçabilidade discursiva. A irredutibilidade e a autonomia desses três eixos perfazem a aporia constitutiva da forma inclusão/exclusão.

A inevitabilidade da interpenetração para a continuação da autopoiese nos sistemas sociais e psíquicos, a discrepância fática de oportunidades de 
vida assim como o modo pelo qual as pessoas são endereçadas no sistema expressam diferentes dimensões do social que atendem a legalidades próprias e que não podem ser aproximadas sem trazer consigo desequilíbrios teóricos.

Entretanto, a teoria de sistemas não desenvolveu esses três eixos de modo equivalente. Há clara dominância da interpenetração no fato de que aspectos empíricos e discursivos da inclusão e da exclusão são discutidos apenas de modo secundário e de acordo com o modelo da interpenetração. Talvez o desequilíbrio mais importante esteja no fato de que endereçabilidade e distribuição são subliminarmente subordinadas à interpenetração. Assim, tem-se justamente a neutralização do potencial crítico da forma inclusão/exclusão, pois a interpretação, enquanto condição operacional para que a comunicação ocorra, impede a comparação interpessoal.

Há muito tempo se conhece a predominância da interpenetração em relação ao nível empírico: dado que se perdeu a presença interativa da sociedade nas interações da sociedade funcionalmente diferenciada, logo, como as interações não dispõem mais de um index para o pertencimento conforme a estratificação, é possível sustentar que a diferenciação funcional do sistema não regula as questões distributivas (Luhmann, I985: I I9). Daí o papel do acaso, conforme já discutido. Assim, de acordo com Luhmann, a desigualdade se reproduz de modo afuncional.

Consideradas meticulosamente, "endereçabilidade" e "interpenetração" descrevem fenômenos completamente diferentes: enquanto a produção de pessoas é uma prestação interna ao sistema, a interpenetração não pertence a sistema nenhum:

Por isso, deve-se encontrar, para a temática clássica da "relação entre indivíduo e sociedade", uma conceitualidade que não recorra a nenhuma das operações internas dos sistemas em questão: nem ao trabalho intelectual consciente e nem à comunicação. Propus chamar de interpenetração o acoplamento operativo e estrutural aqui em jogo (Luhmann, I988: 5I, aspas e grifo no original).

Logo, interpenetração é um acoplamento estrutural; ela não é nem comunicação nem consciência, não pertence nem a um e nem a outro. Em contraposição, as pessoas surgem apenas na comunicação:

Pessoas podem ser endereços para a comunicação. Elas podem ser pressupostas como locais de registro para processos sequenciais complexos de comunicação; a esse respeito são funcionalmente equivalentes à escrita. Elas podem servir como pontos de atribuição para suposições causais e especialmente para atribuição de responsabilidades. Tudo isso, contudo, permanece exclusivamente como realidade comunicativa sem qualquer efeito determinante sobre os processos da consciência (Luhmann, I990: 34 , grifos meus). ${ }^{4}$

Os níveis empírico e discursivo da forma inclusão/exclusão são negligenciados de tal modo, que são lidos implicitamente como interpenetração. Isso tem como consequência o fato de que a forma perde seu caráter crítico, a 
capacidade de poder comparar pessoas por meio de uma oposição binária. A tendência tácita de reduzir inclusão e exclusão unicamente às relações operativas entre indivíduos e sociedade, sistemas da consciência e sistemas sociais invalida a aplicação da forma para a comparação interpessoal. Por esse motivo, alega-se frequentemente que algo como uma exclusão total não pode existir, uma vez que todos participam da sociedade como um todo - há, então, apenas inclusão e a exclusão é subestimada.

Nessa interpretação, a forma ganha uma configuração neutralizada. O desenvolvimento da forma inclusão/exclusão na teoria de sistemas levou, ao fim e ao cabo, a um resultado completamente paradoxal: embora não designe um estado individual (Stichweh, 2002: I06), a compreensão da forma inclusão/ exclusão como interpenetração solapa sua capacidade analítica de estabelecer uma comparação entre pessoas. Embora o objetivo original da forma inclusão/ exclusão fosse justamente apreender as desigualdades (Nassehi, 2004: 329), ela acaba subliminarmente por impedir a comparação interpessoal. É justamente esse desiderato da comparabilidade que é perdido quando a forma só é aplicada no âmbito das relações entre indivíduo e sociedade. A revitalização do potencial crítico da forma inclusão/exclusão exige sua utilização referente à comparação interpessoal. Para tal, a forma pode ser associada à sociologia do conflito, informada por uma leitura da teoria do discurso.

\section{A PERFORMATIVIDADE DA EXCLUSÃO E AS LUTAS POR INCLUSÃO}

Nesta seção esboçaremos um modelo performativo para a fórmula inclusão/ exclusão amparado nas teorias do discurso de Butler, Laclau e Mouffe, e que visa completar a produtividade crítico-política da forma inclusão/exclusão em situações de conflito.

Neste ponto, deve-se destacar a afinidade entre o conceito de "comunicação" de Luhmann e o conceito de "discurso" das novas teorias do discurso (Andersen, 2003). O discurso, no sentido de Laclau e Mouffe, não é um modo da expressão linguística. Não é um ato de fala, uma conversação ou uma conversa no sentido da filosofia da linguagem ou da linguística, mas uma determinada caracterização da sociedade que abrange todas as suas dimensões: a linguística assim como a extralinguística, a esfera da produção, as instituições, as práticas e todos os complexos de sentido possíveis (Laclau \& Mouffe, 200I).

Laclau e Mouffe partem da separação, proveniente de Foucault, do discursivo e do não discursivo e utilizam "discurso" para apreender a totalidade do social. Se levarmos a sério as afirmações segundo as quais a sociedade consiste apenas de comunicação (Luhmann) e/ou de que cada objeto só pode ser produzido no discurso (Laclau e Mouffe), então a seguinte conclusão se impõe: a desigualdade social também só pode se realizar à medida que se articula comunicativa e/ou discursivamente. Por isso, a contradição é apenas aparente, pois a articulação discursiva de práticas hegemônicas não supõe mais uma base eco- 
nômica como fonte da hegemonia (Torfing, I999: 4I). O discurso ganha sua materialidade própria (Demirovi , 2008: 407). As questões de distribuição ganham em significado à medida que são articuladas discursivamente - e ainda mais com base na forma inclusão/exclusão no âmbito de um conflito distributivo.

Se a exclusão for mobilizada politicamente como rubrica retórica para ilustrar problemas distributivos e ao mesmo tempo mediar reivindicações de inclusão, então trata-se aqui de um conflito específico cujo desdobramento porventura pode transformar os padrões de inclusão dos sistemas funcionais. Nessas circunstâncias, a exclusão produz um efeito performativo: ela cria dois lados contrapostos, a saber, "incluídos" e "excluídos", para que a inclusão seja reivindicada. Essa exclusão performativa pode desencadear, por conta disso, uma luta por inclusão. Por isso, as lutas por inclusão apresentam três características essenciais: um antagonismo discursivo estruturado pela performatividade retórica da exclusão; a reivindicação por mais inclusão contestada por aqueles que se veem como já "incluídos"; e a necessidade de uma decisão institucional.

\section{INCLUSÃO E EXCLUSÃO COMO DOIS LADOS DE UM ANTAGONISMO DISTRIBUTIVO}

A performatividade da exclusão designa uma estratégia discursiva em cujo curso a rubrica da exclusão é politicamente apropriada tendo em vista uma aplicação retórico-performativa e combativa para ilustrar problemas de distribuição de modo antagônico. Em situações conflituosas, pode atuar como crítica da diferenciação funcional e de suas consequências nocivas, se aplicada estratégica e discursivamente. Enquanto momentos de um antagonismo articulados discursivamente, inclusão e exclusão podem servir para produzir e ativar pessoas e grupos em situações de conflito. É nesse ponto que se pode reativar o potencial crítico da forma inclusão/exclusão: quando os "excluídos" se apresentam e reivindicam acesso mais amplo aos sistemas funcionais da sociedade. Esse fenômeno pode ser descrito como exclusão performativa: pessoas reivindicam mais acesso à educação, saúde, ao sistema político, mobilizando a rubrica discursiva da exclusão.

Esse enfoque não corresponde à leitura dominante sobre exclusão na teoria de sistemas. Tradicionalmente, esta é concebida como um "fato negativo", uma "não ocorrência" ou um "não evento" (Stichweh, 2000: 96; Nassehi, 2004: 342; Farzin, 2006: 95). De fato, essa perspectiva descreve a execução comunicativa e/ou discursiva de processos de exclusão. Entretanto, sem negar o ganho dessa perspectiva, pode-se argumentar que a relação indivíduo/sociedade serve-lhe novamente de base. Assim, a exclusão resulta em inclusão: "No entanto, desse modo, a exclusão torna-se, na forma da recusa, inclusão, uma vez que, no momento da recusa, a pessoa concernida é da mais alta relevância para o sistema social" (Farzin, 2006: 97). Pensemos no exemplo de uma pessoa em situação de rua nos pedir uma esmola e respondermos "hoje eu não tenho". $\mathrm{Na}$ 
interpretação main stream da teoria de sistemas, não podemos considerar o pedinte excluído da sociedade. Se isso faz sentido na concepção ortodoxa da teoria, ela precisa ser revista. Pois, assim, o conceito de exclusão perde sua força crítica: significa apenas aquilo que não pode acontecer para que algo aconteça. Enquanto pressuposto operativo da formação do sistema, ela parece apreender muito pouco, uma vez que "o momento da exclusão não é suficientemente descrito como um não evento ou um não aparecimento da pessoa social" (Opitz, 2008a: 242). Assim como antes, impera a interpretação da forma inclusão/exclusão como interpenetração.

Uma leitura discursiva da forma inclusão/exclusão possibilita a produção de diferenças com a materialização correspondente de pessoas (Fuchs, I997: 59-60). Dela surgem tanto pessoas quanto marcações de identidade sistemicamente geradas que estruturam expectativas e operam como endereços para atribuições de sentido, assim como corpos. Estes de modo algum estão fora da sociedade, mas "no exterior", uma vez que condensam "identidades da exclusão" (Opitz, 2008a: 246) que, por sua vez, devem ser vistas como unidades que atuam comunicativamente, na mesma medida que as pessoas. Os "excluídos" não devem ser compreendidos aqui como "não pessoas" (Opitz, 20 I 2: I 52), isto é, como "desintegração da forma" ou "catástrofe da forma" (Fuchs, 2007: I49), pois são politicamente ativos à medida que se colocam de modo antagônico em relação aos "incluídos", mobilizando a forma inclusão/exclusão para a comparação interpessoal. Assim, a performatividade da exclusão abandona o nível geral da relação entre indivíduo e sociedade e passa a marcar diferenças entre indivíduos (desigualdades articuladas discursivamente).

Judith Butler (I 997) esclarece como a exclusão é politicamente representada. Butler realiza uma reinterpretação da teoria da linguagem de John L. Austin baseada em Foucault e Derrida, segundo a qual nenhum ato de fala pode ser completamente soberano: antes de ser um ato de vontade subjetivo, o ato performativo e/ou ilocutivo pode ser identificado justamente pelo fato de que uma instabilidade constitutiva lhe é inerente. Esta garante que nenhuma mensagem deva impor ou completar forçosamente aquilo que se reivindica por meio dela, pois todos os enunciados podem ser confrontados e deslegitimados por enunciados contrários. O enunciado não é uma representação do mundo, mas um campo de luta (cf. Bachur, no prelo).

A performatividade discursiva é uma ressignificação ininterrupta conduzida nas operações comunicativas que produzem sentido (Butler, I997: I4), com o pressuposto de que nem o falante/autor nem o contexto podem realizar uma definição compulsória da linguagem, uma vez que o discurso pode solapar a força de definição do contexto e/ou do autor (Butler, I997: 40).

Propomos a interpretação da exclusão como marcação discursiva que, ao ser enunciada, abre um conflito distributivo e, com isso, cria efetivamente um campo de excluídos que precisa ser considerado. A performatividade do dis- 
curso serve de base para a reinterpretação da forma inclusão/exclusão: o lado da exclusão não é um "fato negativo", uma "não ocorrência" ou um "não evento", mas indica a oportunidade de ressignificação política da endereçabilidade no âmbito de uma situação de conflito antagônica na qual se luta por inclusão:

Considere, por exemplo, aquela situação em que sujeitos excluídos de uma vida emancipada pelas convenções dadas, que regem a definição excludente do universal, aproveitem a linguagem da emancipação para colocar em movimento uma 'contradição performativa', reclamando estarem incluídos no universal e expondo assim o caráter contraditório das prévias formulações convencionais do universal. Esse tipo de discurso aparece a princípio impossível ou contraditório, mas ele constitui uma forma de expor os limites das noções correntes de universalidade, e constitui um desafio aos standards existentes de inclusão, que devem se tornar mais expansivos e includentes (Butler, 1997: 89).

Nesses termos, a exclusão é tudo, menos um não evento. É tão constitutiva quanto a inclusão para a produção de identidades no âmbito de discursos antagônicos. O momento da exclusão também deve ser visto como um evento comunicativo que configura política e discursivamente uma luta por inclusão, posto que a exclusão se liga a uma corrente de comunicação e a leva adiante de modo produtivo. Uma mensagem de recusa que vise executar uma exclusão não é um ato soberano que converte a exclusão em inclusão, no sentido puramente operativo, como pretendem os luhmannianos ortodoxos. Ela pode ser replicada sem que o pretenso excluído simplesmente negue ou assuma mimeticamente o status a ele atribuído. Fica aberta ao excluído uma alternativa crítica de apanhar o status excludente para dirigir uma contramensagem na direção de uma visibilização discursiva das fronteiras entre um "dentro" e um "fora" na sociedade. Logo, inclusão e exclusão estruturam dois lados de um agrupamento antagônico, o que abre o caminho para que se possa comparar pessoas e criticar politicamente tanto problemas quanto padrões de distribuição.

Com isso, a atenção não se volta para a "política da sociedade", mas para o político (Stäheli, 2000: 249; Marchart, 20I0: 206). À primeira vista, a discussão sobre o político e a descrição de conflitos distributivos baseada na forma inclusão/exclusão encontram-se em registros distintos, pois o "exterior constitutivo" da sociedade (Laclau \& Mouffe, 200I: I 26) não diz respeito imediato à "exclusão constitutiva" do discurso (Stäheli, 2000: 54), mas às condições de possibilidade do social. ${ }^{5}$ Apesar disso, algumas sugestões fornecem direções possíveis para a forma inclusão/exclusão, problematizando-a com pessoas para dentro e/ou fora dos sistemas funcionais (Opitz, 2008a; Stäheli, 2008: I I4-I I 5; Opitz, 20I2).

Elas não perdem a versão binária de uma forma de dois lados, mas deixam de descrever as condições de possibilidade operativas dos acoplamentos estruturais e passam a descrever momentos discursivos que marcam posicionamentos diferenciais em uma articulação (Laclau \& Mouffe, 200I: I05). Nesse contexto, "articulação" significa "qualquer prática que estabelece uma relação entre 
elementos de modo que sua identidade é modificada como resultado da prática de articulação" (Laclau \& Mouffe 200I: I05). Nesse contexto, inclusão e exclusão são momentos de uma articulação discursiva que geram um antagonismo estruturado a partir de um conflito distributivo: uns têm mais acesso às prestações de um determinado sistema social enquanto outros têm menos; estes últimos tomam a palavra e reivindicam participação - que é resistida pelos já estabelecidos.

\section{INCLUSÃO E EXCLUSÃO COMO MOMENTOS DE UM CONFLITO DISTRIBUTIVO}

Portanto, a forma inclusão/exclusão pode servir para gerar uma oposição binária objetivando mediar reivindicações de inclusão, exigir e refutar justificações para discriminações experimentadas empiricamente, assim como produzir e criticar discursivamente causalidades a esse respeito. Em suma, trata-se de agrupamentos ad hoc que só podem acontecer discursivamente: a forma inclusão/exclusão pode ser aplicada para marcar uma situação de "nós/eles" ou "mais/menos", por assim dizer. Por isto a forma é performativa: ela gera aquilo que ela nomeia - incluídos de um lado, excluídos de outro. A criação dessa separação é performativa pelo fato de que ambos os polos são construídos no discurso: não correspondem às fronteiras operativas de um sistema, uma vez que não se referem à diferenciação "genuína" sistema/ambiente; apesar disso, eles geram algo como fronteiras "artificiais", que podem ser problematizadas posto que implementam marcações retóricas linguístico-políticas.

Especialmente importante para essa perspectiva é o conceito de significante vazio: "Um significante vazio é stricto sensu um significante sem um significado" (Laclau, I996: 36). Eles são tão amplamente esvaziados de seus significados particulares, que alegam expressar uma unidade imaginária do discurso, com a consequência de que uma particularidade reivindica paradoxalmente uma representação universal (Stäheli, 200I: 20I). Propõe-se aqui que a inclusão também pode ocupar a posição de um significante vazio quando traz em seu bojo uma proibição da exclusão no sentido de Luhmann. Dado que a inclusão se desdobra justamente ao invisibilizar o lado negativo de si mesma, como se apenas um dos lados da forma fosse operacional (Ruda, 2008: 21 2). Entretanto, desse modo, a teoria de sistemas de Luhmann não apenas neutraliza o lado da exclusão da forma, como também esvazia o significado do conceito de inclusão.

Em uma luta por inclusão, ambos os significantes postulam ao mesmo tempo um significado (a participação nas comunicações sistêmicas), de modo que se instala um paradoxo. A esse respeito, contudo, a "política da reversão do paradoxo" (Stäheli, 200o) assume um significado ainda mais diferenciado: a desconstrução da inclusão como significante vazio, de modo que reivindicações de inclusão podem ser analisadas em uma versão antagônica.

Os posicionamentos atuais e suas classificações contingentes são determinados de modo antagônico e performativo: aqueles que se veem como "in- 
cluídos" imputam aos "excluídos" a ameaça a sua própria situação; ao passo que aqueles que se imaginam "excluídos" atribuem aos "incluídos" o impedimento de suas reivindicações de inclusão. Nessas circunstâncias, podem ser realizados deslocamentos políticos. Assim, abre-se a possibilidade de descrever os significantes inclusão e exclusão em sua performance para a consolidação de identidades em conflitos distributivos.

Desigualdade e conflitos distributivos não pressupõem níveis extracomunicativos, uma vez que diferenças empíricas entre indivíduos só produzem sentido social ao ser comunicadas. Se a sociedade pode ser caracterizada pela complexidade e só pode consistir de comunicação, os sistemas funcionais têm de pôr cada vez mais possibilidades de comunicação à disposição do que são capazes de realizar. Logo, a formação do sistema deve criar para si algum tipo de seleção e, por isso, também uma certa distribuição das prestações do sistema. Em todo caso, tal distribuição deve aparecer comunicativamente, pois "a estrutura [de um sistema] redistribui as oportunidades de comunicação [...] entre os participantes" (Luhmann, i984: 565).

De fato, a criação da diferenciação inclusão/exclusão tem de supor "condições médias de vida" (Demirovi , 2008: 405) que só podem ser definidas de modo discursivo/comunicativo, mas também sempre conflitivo

O que está em jogo é sempre a hegemonia, ou seja, a dominação dos modos devida de grupos privilegiados que se podem apoiar no assentimento de muitos; e que só podem estabelecer sua espécie de condução da vida ao excluir os outros como aberrantes (Demirovi , 2008: 405).

Uma luta por inclusão busca deslocar essa linha à medida que os padrões de inclusão e exclusão são politizados criticamente. Ao contrário do acaso e da intensificação espontânea, uma luta por inclusão significa a politização deliberada dos critérios de acesso aos sistemas funcionais. Assim, a intensificação do conflito não se dá apenas em uma dimensão quantitativa, mas também assume um aspecto qualitativo, pois a luta por inclusão insta a uma tomada oficial de decisão.

\section{O CONFLITO, EM SUA VERSÃO DESPOLITIZADA, NÃO PERMITE $O$ TRATAMENTO ADEQUADO DE QUESTÕES DE INCLUSÃO E EXCLUSÃO}

Em regra, em relações hierárquicas dentro de organizações ou em incontáveis negociações que ocorrem nos sistemas políticos, econômicos e científicos, a recusa e o dissenso, além de problemáticos, também são estabilizados e até mesmo regulamentados institucionalmente - e isso para além do "não" dito. Tanto as recusas como o dissenso pertencem às operações normais da autopoiese, e um parasitismo de modo algum está em questão. Mas tais hipóteses não têm nada a ver com questões de distribuição. De qualquer forma, a teoria de sistemas tem de conseguir distinguir conflitos distributivos, de um lado, e o percurso cotidiano e prosaico da comunicação, de outro. A repolitização do 
conflito exige que a problematização das "fronteiras do sistema" seja erigida de acordo com uma regra dentro/fora baseada na forma inclusão/exclusão, pondo em marcha uma luta por inclusão que deve ser decidida.

Na perspectiva da teoria de sistemas, todos os conflitos são estruturados pela diferenciação dos processos comunicativos segundo a qual expectativas contrapostas e incompatíveis são comunicadas e devem coexistir temporariamente. Quão estável ou precária, efêmera ou duradoura será essa coexistência depende de como a sociedade mobiliza seus mecanismos de processamento e/ ou resolução de conflitos, mas também da intensidade com a qual esses mecanismos podem ser acoplados estruturalmente uns aos outros. A complexidade, por sua vez, quer dizer que nem todas as reivindicações de inclusão podem ser realizadas.

Daí a luta por inclusão. Lutas por inclusão descrevem, por conseguinte, a constituição discursiva de conflitos distributivos em que emergem posições antagônicas referentes à participação desigual nas operações dos sistemas sociais, com a consequência de que padrões estabelecidos de inclusão e exclusão podem ser politicamente desestabilizados ou modificados por uma decisão política.

Uma luta por inclusão somente se estabelece se o conflito levar à desestabilização das condições de inclusão no sistema principal ou em outros sistemas funcionais. Dota o sistema principal de um antagonismo agudo que estabelece a necessidade de uma decisão institucional cujo objeto é uma possível modificação dos padrões de inclusão e exclusão.

De acordo com Luhmann, conflitos são estruturados em dois aspectos: ou por meio do direito, ou pelos movimentos de protesto. Todavia, a luta por inclusão é um híbrido: ela pode até depender de uma mobilização coletiva, mas visa a uma decisão institucional oficial para tentar modificar os padrões. Ela torna o sistema político sensível a "constelações da hegemonia" (Reckwitz, 2008: 70) e pode levar a decisões que não se limitam necessariamente às fronteiras operativas de um único sistema funcional.

Tais decisões podem até ser tomadas pelo aparato do Estado de bem-estar (Halfmann, 2002), mas não necessariamente; elas podem decorrer de acordo tanto com o circuito de poder oficial quanto com o não oficial da política (Luhmann, I984). Podem tanto produzir estruturas ad hoc quanto provocar modificações permanentes nos padrões de inclusão de um sistema, dependendo de quanta tensão a luta produz.

\section{CONCLUSÃO E COMENTÁRIOS FINAIS}

$\mathrm{Na}$ aplicação crítico-política de uma retórica de exclusão, no sentido da estruturação de lutas antagônicas por inclusão, a binariedade ganha um significado ampliado em termos da teoria de sistemas, que ilumina seu potencial crítico.

O modelo de uma teoria performativa da forma inclusão/exclusão em questões de distribuição afirma que os excluídos de modo algum são politica- 
mente incapazes; muito pelo contrário, sua força está situada justamente na possibilidade de tomar a palavra enquanto excluídos para criticar as condições dadas de inclusão.

Se essa forma é compreendida como interpenetração, então ela não tem significado algum para a discussão de problemas distributivos. O potencial crítico que ela tem está situado na orientação para relações interpessoais, na problematização política das relações entre indivíduos referente à participação nos sistemas funcionais da sociedade.

A mobilização retórico-política da exclusão tem um significado decisivo para a constituição de pessoas, grupos e conflitos: lutas por inclusão designam um tipo autônomo de conflito, cujo motivo de intensificação não é elaborado apenas comunicativamente. Logo, não se trata da complementação de uma determinação temática da intensificação do conflito, mas da estruturação performativa de um antagonismo.

A exclusão é apropriada de modo retórico-político para mediar as reivindicações de inclusão. No decorrer dessa articulação discursivo-performativa, ambas marcam os lados de uma diferenciação antagônica que serve à estruturação de grupos antagônicos e com base na qual se revelam problemas distributivos.

Tal modelo performativo parece não apenas inaugurar uma perspectiva complementar à conceitualização da teoria de sistemas da forma inclusão/ exclusão, mas também oferecer a possibilidade de tornar a forma aplicável em estudos de caso e/ou pesquisas empíricas.

O fato de que os sistemas funcionais regulam seus próprios critérios de inclusão não invalida seu combate - é neles que se situam a autonomia e a proeminência do político. A demarcação de fronteiras e a decisão sobre "quem pertence a qual lado" só podem resultar da problematização conflituosa de constelações hegemônicas. Inclusão e exclusão são, por conseguinte, momentos discursivos da articulação de um conflito cujo cerne é a demarcação de uma fronteira interna/externa na sociedade de acordo com uma constelação política que agrega de modo constitutivo inclusão, exclusão, conflito e problemas distributivos.

Recebido em 07/2/2020 | Revisado em 03/3/2020 | Aprovado em Io/3/2020

João Paulo Bachur é doutor em ciência política pela USP, com pós-doutorado em filosofia pela Universidade Livre de Berlim, como bolsista da Fundação Alexander von Humboldt. Professor e coordenador do programa de pós-graduação stricto sensu em direito constitucional do Instituto Brasiliense de Direito Público. Professor do Instituto de Ensino e Pesquisa (Insper). 


\section{NOTAS}

I As teses aqui sustentadas foram apresentadas pela primeira vez em 6 de dezembro de 2012 por ocasião da jornada "Die gespaltene Gesellschaft: Sozialwissenschaftliche Perspektiven auf alte und neue soziale Ungleichheiten" ["A sociedade cindida: perspectivas das ciências sociais sobre velhas e novas desigualdades sociais"], da seção "Desigualdade social" da Sociedade Austríaca de Sociologia na Universidade Johannes Kepler, em Linz, Áustria. Originalmente escrito em alemão, com o título "Die Performativität der Exklusion und die Kämpfe um Inklusion: Verteilungsfragen anhand einer systemtheoretischen Unterscheidung", o texto foi desde então amplamente reelaborado. Agradeço a Sérgio Costa, Andreas Fischer-Lescano, Marcelo Neves, Regina Kreide, Kolja Moeller e Johan Horst os solícitos apontamentos a uma versão prévia deste texto. Agradeço a Eduardo Altheman C. Santos a tradução do manuscrito original. Pelo apoio financeiro, agradeço a Fundação Alexander von Humboldt.

2 Nesse aspecto, a teoria de sistemas e a teoria do agir comunicativo assemelham-se de modo surpreendente: "Segundo Luhmann e Habermas, só se observa um conflito quando uma comunicação é contraditada. O que decorre pode ser compreendido como discurso ou como sistema social em que conflitos, em regra, atraem para si uma disputa verbal-linguística, uma vez que, de outro modo, não poderiam formar nem um discurso nem um sistema social. O conflito, enquanto fato empírico, dissipar-se-ia tão rapidamente quanto surgiu" (Bonacker, I997: I05, grifos meus).

3 Cf. aqui Bachur (2013).

4 Deve ser mencionado aqui, entretanto, que Luhmann define "pessoa" no sentido do acoplamento estrutural (Luhmann, I99I: I46). Isso representa menos uma guinada de perspectiva do que uma evidência da preponderância subliminar da interpenetração.

5 Lê-se de modo muito claro: "Minha compreensão da exclusão não se refere ao problema da inclusão/exclusão social (tal como elaborado em Luhmann N., I995), isto é, trata-se de uma análise anterior à exclusão de pessoas 
ou grupos" (Stäheli, I996: 72, nota 9). E também Marchart (2008: 37I): "Esse modo mais fundamental [da exclusão] normalmente não está associado ao conceito de exclusão e/ou inclusão, que assume funções de atribuição dentro da sociedade, mas é apreendido acima de tudo pela lógica das formas de Spencer-Brown".

\section{REFERÊNCIAS BIBLIOGRÁFICAS}

Andersen, Niels Åkerstrøm. (2003). Discursive analytical strategies: understanding Foucault, Koselleck, Laclau, Luhmann. Bristol: Policy Press.

Bachur, João Paulo. (no prelo). Para uma sociologia da ressignificação. In: Direito e praxis.

Bachur, João Paulo. (2013). O Estado de bem-estar em Hayek e Luhmann. Tempo Social, 25/2, p. I79-2I3.

Bachur, João Paulo. (2012). Inclusão e exclusão na teoria de sistemas sociais: um balanço crítico. BIB, 73/I, p. 55-83.

Bohn, Cornelia. (2008). Inklusion und Exklusion: Theorien und Befunde. Von der Ausgrenzung aus der Gemeinschaft zur inkludierenden Exklusion. Soziale Systeme. Zeitschrift für soziologische Theorie, I4/2, S. I7I-I9O.

Bohn, Cornelia. (2006). Inklusion, Exklusion und die Person. Konstanz: UVK.

Bohn, Cornelia. (200I). Inklusionsindividualität und Exklusionsindividualität. In: Bohn, Cornelia; Willems, Herbert (Hg.). Sinngeneratoren: Fremd- und Selbstthematisierung in soziologisch-historischer Perspektive. Konstanz: UVK, S. I59-I76.

Bohn, Cornelia \& Hahn, Alois. (2002). Patterns of inclusion and exclusion: property, nation and religion. Soziale Systeme. Zeitschrift für soziologische Theorie, 8/I, S. 8-26.

Bonacker, Thorsten. (I997). Kommunikation zwischen Konsens und Konflikt. Möglichkeiten und Grenzen gesellschaftlicher Rationalität bei Jürgen Habermas und Niklas Luhmann. Oldenburg: BIS/ Uni-Oldenburg.

Butler, Judith. (I997). Excitable speech: a politics of the performative. New York/London: Routledge.

Dahrendorf, Ralf. (I990). Class and class conflict in industrial society. Stanford: Stanford University Press. 
Demirović, Alex. (2008). Reibungen an der Normalität: Exklusion und die Konstitution der Gesellschaft. Soziale Systeme. Zeitschrift für soziologische Theorie, I4/2, S. 397-4I7. Farzin, Sina. (2006). Inklusion/Exklusion: Entwicklungen und Probleme einer systemtheoretischen Unterscheidung. Bielefeld: Transcript.

Fuchs, Peter. (2007). Das Maß aller Dinge. Eine Abhandlung zur Metaphysik des Menschen. Weilerswist: Velbrück Wissenschaft.

Fuchs, Peter. (1997). Adressabilität als Grundbegriff der soziologischen Systemtheorie. Soziale Systeme. Zeitschrift für soziologische Theorie, 3/I, S. 57-79.

Gertenbach, Lars. (2008). Ein, Denken des Außen: Michel Foucault und die Soziologie der Exklusion. Soziale Systeme. Zeitschrift für soziologische Theorie, I4/2, S. 308-328.

Giegel, Hans-Joachim. (1998). Gesellschaftstheorie und Konfliktsoziologie. In: Giegel, Hans-Joachim (Hg.). Konflikt in modernen Gesellschaften. Frankfurt am Main: Suhrkamp, S. 9-28. Göbel, Markus \& Schmidt, Johannes F. K. (I998). Inklusion/ Exklusion: Karriere, Probleme und Differenzierung eines systemtheoretischen Begriffspaars. Soziale Systeme. Zeitschrift für soziologische Theorie, 4/I, S. 87-II8.

Halfmann, Jost. (2002). Der moderne Nationalstaat als Lösung und Problem der Inklusion in das politische System. In: Hellmann, Kai-Uwe; Schmalz-Bruns, Rainer (Hg.). Theorie der Politik: Niklas Luhmanns politische Soziologie. Frankfurt am Main: Suhrkamp, S. 26I-286.

Hayek, Friedrich August von. (1976). Law, legislation and liberty II. Chicago: University of Chicago Press.

Hayek, Friedrich August von. (1973). Law, legislation and liberty I. Chicago: University of Chicago Press.

Kronauer, Martin. (2010). Exklusion: Die Gefährdung des Sozialen im hoch entwickelten Kapitalismus, 2. Aufl. Frankfurt am Main/New York: Campus.

Laclau, Ernesto. (1996). Emancipation(s). London/New York: Verso.

Laclau, Ernesto \& Mouffe, Chantal. (200I). Hegemony and socialist strategy: towards a radical democratic politics, 2. Aufl. London/New York: Verso. 
Link, Jürgen \& Parr, Rolf (Hg.). (2004). Foucault mal Luhmann: Welche Produkte? KultuRRevolution, 47.

Luhmann, Niklas. (2000a). Die Politik der Gesellschaft (herausgegeben von André Kieserling). Frankfurt am Main: Suhrkamp.

Luhmann, Niklas. (1997). Die Gesellschaft der Gesellschaft. Frankfurt am Main: Suhrkamp.

Luhmann, Niklas. (I995a). Inklusion und Exklusion. In: Soziologische Aufklärung 6, 2. Aufl. Wiesbaden: VS, S. 22625 I.

Luhmann, Niklas. (I995b). Jenseits von Barbarei. In: Gesellschaftsstruktur und Semantik: Studien zur Wissenssoziologie der modernen Gesellschaft, Bd. 4. Frankfurt am Main: Suhrkamp, S. I38-150.

Luhmann, Niklas. (I995C). Kausalität im Süden. Soziale Systeme. Zeitschrift für soziologische Theorie, I/I, S. 7-28.

Luhmann, Niklas. (I99I). Die Form, Person. In: Soziologische Aufklärung 6, 2. Aufl. Wiesbaden: VS, S. I37-I48.

Luhmann, Niklas. (I990). Die Wissenschaft der Gesellschaft. Frankfurt am Main: Suhrkamp.

Luhmann, Niklas. (1989). Individuum, Individualität, Individualismus. In: Gesellschaftsstruktur und Semantik: Studien zur Wissenssoziologie der modernen Gesellschaft, Bd. 3 . Frankfurt am Main: Suhrkamp, S. I49-258.

Luhmann, Niklas. (1988). Wie ist Bewußtsein an Kommunikation beteiligt? In: Soziologische Aufklärung 6, 2. Aufl. Wiesbaden: VS, S. 38-54.

Luhmann, Niklas. (I985). Zum Begriff der sozialen Klasse. In: Ideenevolution: Beiträge zur Wissenssoziologie (herausgegeben von André Kieserling). Frankfurt am Main: Suhrkamp, S. 72-I3I.

Luhmann, Niklas. (1984). Soziale Systeme: Grundriß einer allgemeinen Theorie. Frankfurt am Main: Suhrkamp.

Luhmann, Niklas. (198I). Politische Theorie im Wohlfahrtsstaat. München: Olzog.

Luhmann, Niklas. (I980a). Theoretische Orientierung der Politik. In: Soziologische Aufklärung 3, 4. Aufl. Wiesbaden: VS, S. 329-335. 
Luhmann, Niklas. (I980b). Gesellschaftliche Struktur und semantische Tradition. In: Gesellschaftsstruktur und Semantik: Studien zur Wissenssoziologie der modernen Gesellschaft, Bd. I. Frankfurt am Main: Suhrkamp, S. 9-7I.

Luhmann, Niklas. (1977). The Differentiation of Society. In: The Differentiation of Society, Übers. v. Stephen Holmes; Charles Larmore. New York: Columbia University Press, S. 229254.

Luhmann, Niklas. (1975). Evolution und Geschichte. In: Soziologische Aufklärung 2, 5. Aufl. Wiesbaden: VS, S. I87-2I I. Luhmann, Niklas. (1965). Grundrechte als Institution. Ein Beitrag zur politischen Soziologie. Berlin: Duncker \& Humblot.

Marchart, Oliver. (2013). Das unmögliche Objekt: Eine postfundamentalistische Theorie der Gesellschaft. Berlin: Suhrkamp. Marchart, Oliver. (2010). Die politische Differenz: Zum Denken des Politischen bei Nancy, Lefort, Badiou, Laclau und Agamben. Berlin: Suhrkamp.

Marchart, Oliver. (2008). Ungesellschaftliche Gesellschaftlichkeit: Exklusion und Antagonismus bei Lévi-Strauss, unter Berücksichtigung von Lacan, Laclau und Luhmann. Soziale Systeme. Zeitschrift für soziologische Theorie, I4/2, S. 370-396.

Marchart, Oliver. (2002). On drawing a line. Politics and the significatory logics of inclusion/exclusion. Soziale Systeme. Zeitschrift für soziologische Theorie, 8/I, S. 69-87.

Messmer, Heinz. (2003). Konflikt und Konfliktepisode: Prozesse, Strukturen und Funktionen einer sozialen Form. Zeitschrift für Soziologie, 32/2, S. 98-I22.

Nassehi, Armin. (2004). Inkusion, Exklusion, Ungleichheit. Eine kleine theoretische Skizze. In: Schwinn, Thomas (Hg.). Differenzierung und soziale Ungleichheit: Die zwei Soziologien und ihre Verknüpfung. Frankfurt am Main: Humanities Online, S. 323-352.

Nollmann, Gerd. (1997). Konflikte in Interaktion, Gruppe und Organisation: Zur Konfliktsoziologie der modernen Gesellschaft. Opladen: Westdeutscher.

Opitz, Sven. (2012). An der Grenze des Rechts: Inklusion/ Exklusion im Zeichen der Sicherheit. Weilerswist: Velbrück Wissenschaft. 
Opitz, Sven. (2008a). Die Materialität der Exklusion: Vom ausgeschlossenen Körper zum Körper des Ausgeschlossenen. Soziale Systeme. Zeitschrift für soziologische Theorie, I4/2, S. 229-253.

Opitz, Sven. (2008b). Exklusion: Grenzgänge des Sozialen. In: Moebius, Stephan; Reckwitz, Andreas (Hg.). Posts trukturalistische Sozialwissenschaften. Frankfurt am Main: Suhrkamp, S. I75-193.

Reckwitz, Andreas. (2008). Subjekt. Bielefeld: Transcript. Ruda, Frank. (2008). Alles verpöbelt sich zusehends! Namenlosigkeit und generische Inklusion. Soziale Systeme. Zeitschrift für soziologische Theorie, I4/2, S. 210-228.

Schneider, Wolfgang Ludwig. (1994). Die Beobachtung von Kommunikation: Zur kommunikativen Konstruktion sozialen Handelns. Opladen: Westdeutscher.

Schroer, Markus. (20I0). Funktionale Differenzierung versus soziale Ungleichheit: Ein Beitrag zur Debatte über die Grundstruktur der modernen Gesellschaft. In: Kneer, Georg; Moebius, Stephan (Hg.). Soziologische Kontroversen: Beiträge zu einer anderen Geschichte der Wissenschaft vom Sozialen. Berlin: Suhrkamp, S. 29I-313.

Spencer-Brown, George. (I969). Laws of form. New York: Bantam.

Stäheli, Urs. (2008). System: Unentscheidbarkeit und Differenz. In: Moebius, Stephan; Reckwitz, Andreas (Hg.). Poststrukturalistische Sozialwissenschaften. Frankfurt am Main: Suhrkamp, S. I08-I23.

Stäheli, Urs. (200I). Die politische Theorie der Hegemonie: Ernesto Laclau und Chantal Mouffe. In: Brodocz, André; Schaal, Gary S. (Hg.). Politische Theorien der Gegenwart: Eine Einführung, Bd. 2. Opladen: Leske/Budrich, S. 193-223.

Stäheli, Urs. (2000). Sinnzusammenbrüche: Eine dekonstruktive Lektüre von Niklas Luhmanns Systemtheorie. Weilerswist: Velbrück Wissenschaft.

Stäheli, Urs. (I996). From victimology towards parasitology. Recherches sociologiques, 27/2, S. 59-80.

Stichweh, Rudolf. (2005). Inklusion und Exklusion: Studien zur Gesellschaftstheorie. Bielefeld: Transcript. 
Stichweh, Rudolf. (2002). Strangers, inclusions, and identities. Soziale Systeme. Zeitschrift für soziologische Theorie, 8/I, S. IOI-IO9.

Stichweh, Rudolf. (2000). Die Weltgesellschaft. Soziologische Analysen. Frankfurt am Main: Suhrkamp.

Streeck, Wolfgang. (20II). The crises of democratic capitalism. New Left Review, 7I, p. 5-29.

Torfing, Jacob. (1999). New theories of discourse: Laclau, Mouffe and Žižek. Oxford: Blackwell. 
Palavras-chave

Conflito;

inclusão;

exclusão;

teoria do discurso;

teoria dos sistemas.

Keywords

Conflict;

inclusion;

exclusion;

theory of discourse;

systems theory.

\section{A PERFORMATIVIDADE DA EXCLUSÃO E AS LUTAS} POR INCLUSÃO: QUESTÕES DISTRIBUTIVAS A PARTIR DA TEORIA DE SISTEMAS SOCIAIS

\section{Resumo}

O artigo oferece uma autorreflexão crítica dentro da teoria de sistemas e examina programaticamente a seguinte questão: como a inclusão e a exclusão podem ser incorporadas a uma teoria do conflito cujo cerne é constituído de questões distributivas. Para tanto, propõe uma reinterpretação teórico-discursiva da forma inclusão/exclusão orientada para o conflito, de acordo com a qual a inclusão e a exclusão poderiam ser descritas como articulações políticas performativas, no sentido das teorias do discurso contemporâneas.

THE PERFORMATIVITY OF EXCLUSION AND STRUGGLES FOR INCLUSION: DISTRIBUTIVE QUESTIONS BASED ON SOCIAL SYSTEMS THEORY

\section{Abstract}

The article offers a critical self-reflection within the theory of systems and explores the following question: how can inclusion and exclusion be incorporated into a theory of conflict whose core is constituted by distributive issues?

To this end, it proposes a theoretical-discursive reinterpretation of the inclusion/exclusion model oriented towards conflict, in which inclusion and exclusion can be described as performative political articulations, in the sense of contemporary theories of discourse. 